\title{
Histological Changes in Archived Piglet Tissues from a Herd Sub Clinically Infected with Porcine Circo Virus Type 2 (PCV2) Preceding a Fulminant Episode of Stillbirths and Neonatal Mortality
}

\author{
S. Hemalatha ${ }^{1}$, Anbu Kumar Karuppanan ${ }^{2}$, S. Jaisree ${ }^{1 *}$, C. Sreekumar ${ }^{3}$, M. Murugan ${ }^{3}$, \\ Parimal Roy ${ }^{1}$, H. Gopi ${ }^{3}$ and K. Kumanan ${ }^{1}$ \\ ${ }^{1}$ Central University Laboratory, Centre for Animal Health Studies, Tamil Nadu Veterinary and Animal Sciences University, \\ Madhavaram Milk Colony, Chennai, INDIA \\ ${ }^{2}$ Vaccine Research Centre - Viral Vaccines, Centre for Animal Health Studies, Tamil Nadu Veterinary and Animal Sciences \\ University, Madhavaram Milk Colony, Chennai, INDIA \\ ${ }^{3}$ Post Graduate Research Institute in Animal Sciences, Tamil Nadu Veterinary and Animal Sciences University, \\ Kattupakkam, INDIA \\ *Corresponding author: S Jaisree; E-mail: jaisree.s@tanuvas.ac.in
}

Received: 04 June, 2020

Revised: 25 June, 2020

Accepted: 11 July, 2020

\begin{abstract}
This study reports the histological lesions in archived formalin fixed piglet tissues from a herd subclinically infected with PCV2 that progressed to showing PCV2 associated systemic disease and later experienced a major fulminating episode of PCV2 induced reproductive failure characterized with abortions, mummified fetuses, still births and neonatal mortality. Lymphoid cell depletion in one or two lymph nodes were observed in subclinical infection. In PCV2 associated systemic disease multiple lymph nodes revealed variable degree of lymphoid cell depletion and necrosis with multinucleate giant cells, syncytia formation and intracytoplasmic inclusions. Histopathological changes in other organs included multifocal, severe lymphoid depletion and extensive necrosis in spleen; multifocal coagulative necrosis in Peyer's patches; diffuse lymphohistiocytic interstitial pneumonia in lungs; multifocal necrotizing hepatitis in liver. A progressive shift in lesion type was noticed when the infection progressed from subclinical infection to PCV2 associated systemic disease. PCR assay performed with DNA extracted from formalin fixed tissues showed specific amplification product of 620 base pairs, confirming the presence of PCV2 ORF2 genome in the tissues

\section{HIGHLIGHTS}

(0 This paper describes subclinical and clinical PCV2 infection among piglets.

(0 Moderate diffuse lymphoid depletion in lymphoid tissues were observed in subclinical infection

(0 Severe lymphoid depletion with viral inclusions and syncytia were characteristic of clinical PCV2 infection.
\end{abstract}

Keywords: PCV2, Histopatholgy, Clinical and subclinical infection, PCR from archival tissue

Porcine circoviruses (PCV) are small non enveloped single stranded circular DNA virus that are widespread in the commercial swine population and has been associated with several disease complexes. Porcine circovirus is classified into PCV1, PCV2 and PCV3. PCV1 and PCV2 were identified earlier in 1970 and 1990 respectively. PCV3 was recently identified in 2016 (Zhai et al., 2016). PCV1 is apathogenic in pigs. PCV2 and PCV3 cause systemic disease in pigs. Porcine circovirus has been associated with outbreaks of Post Weaning Multisystemic
Wasting Syndrome (PMWS), porcine dermatitis and nephropathy syndrome, porcine respiratory disease complex, reproductive disease and enteritis (Seagles, 2012).

How to cite this article: Hemalatha, S., Karuppanan, A.K., Jaisree, S. Sreekumar, C., Murugan, M., Roy, P., Gopi, H. and Kumanan, K. (2020) Histological changes in archived piglet tissues from a herd sub clinically infected with porcine circo virus type 2 (PCV2) preceding a fulminant episode of stillbirths and neonatal mortality. J. Anim. Res., 10(4): 501-505. Source of Support: None; Conflict of Interest: None क) 
PCV2 infection induced was first recognized in swine herds in Canada in 1991 and has since been reported worldwide. The etiology of PMWS was first established in 1997. PMWS develops more often in pigs 5-12 weeks of age (Allan and Ellis, 2000; Segales et al., 2004). PCV2 has tropism for the cells of the monocytic/macrophage lineage and the lymphocytopenia and immunosuppression that occurs following infection results in concomitant infections that complicate the diagnosis. Porcine circo virus type 2 (PCV2) is a major cause of disease in farmed pigs across the world. However, the impact of PCV2 infections was unreported from the Indian subcontinent until recently.

The current study reports the histological lesions in archived, formalin fixed piglet tissues from a herd subclinically infected with PCV2 that progressed to showing PCV2 associated systemic disease and later experienced a major fulminating episode of PCV2 associated reproductive failure characterized with abortions, mummified fetuses, still births and neonatal mortality which was reported earlier (Karupannan et al., 2014).

\section{MATERIALS AND METHODS}

\section{Study samples}

Tissue samples were collected over a period of one year from thirty-two dead weanling or post-weaned piglets without clinical signs or that showed clinical signs of unthriftiness and weakness from a piggery unit at the Tamil Nadu Veterinary and Animal Sciences University's research farm at Kattupakkam, Chennai in Southern India. The farm housed Large White Yorkshire and cross bred Indian herd. The representative tissue samples consisted of liver, kidney, heart, lung, spleen, lymph nodes and intestine.

\section{Histopathological examination}

The tissue samples were dehydrated and paraffin embedded. The tissue samples were trimmed to 2-3 $\mathrm{mm}$ thickness, dehydrated in grades of alcohol, cleared in xylene and the paraffin embedded tissues were cut at 4-5 $\mu$ thickness, stained with Harri's haematoxylin and eosin method and evaluated.

\section{PCR from formalin fixed tissue}

PCV2 genome was extracted from the formalin fixed tissues using Qiagen DNeasy Blood and Tissue Kit (Qiagen, Valencia, CA, USA) following the manufacturer's instructions. Presence of PCV2 genomic DNA was specifically detected by polymerase chain reaction (PCR) assay using the primers for ORF2 gene (Forward 5'- CAGCCATCTTGGCCAGATC - 3'and Reverse 5'-CTGAATTGTACATACATGGTTACACG-3') (Kim and Chae, 2004). The PCR cycle conditions were initial denaturation at $94^{\circ} \mathrm{C}$ for 4 minutes followed by annealing at $55^{\circ} \mathrm{C}$ for 20 seconds, extension at $72^{\circ} \mathrm{C}$ for 1 minute, denaturation at $98^{\circ} \mathrm{C}$ for 20 seconds for 35 cycles. PCR products were separated in a $1.5 \%$ agarose gel and documented using Bio-Rad XR+ gel doc imager.

\section{RESULTS AND DISCUSSION}

Tissue samples of asymptomatic piglets revealed mild to moderate, multifocal to diffuse variable degree of lymphoid depletion and reticuloendothelial cell hyperplasia in the paracortical or follicular zones in the mesenteric and mediastinal lymph nodes (Fig.1A) with a few lymph nodes showing one or two germinal centres formation. Spleen revealed diffuse lymphoid depletion with reticulum cell hyperplasia (Fig.1B). The liver showed mild multifocal coagulative necrosis with lymphoplasmacytic infiltration around the portal areas (Fig.1C). Mild focal lymphoplasmacytic infiltration was observed in the interstitium of corticomedullary region (Fig.1D). Lungs showed subtle changes with congestion and edema or mild focal to diffuse acute bronchointerstitial pneumonia. The lesions in asymptomatic piglets were mild and mostly focal and the multiorgan involvement was rarely noticed in a single piglet. Hence, the lesions were corroborated with the subclinical form of PCV2 infection as described by Krakowka et al. (2005) and Opriessnig et al. (2007).

In the tissue samples of piglets with unthriftiness and poor body weight gain, the lesions observed were multifocal to diffuse coagulative necrosis of lymphoid cells in the follicular zones (Fig.2A) with extensive proliferation of reticuloendothelial cells and infiltration with numerous plasma cells and macrophages with the presence of multinucleate giant cells in the lymph nodes (Fig.2B) which was a consistent finding. Syncytia formation (Fig.2C) and presence of spherical bluish pink, sharply demarcated, 
variably sized botryoid-inclusions in the cytoplasm of macrophages was a significant finding (Fig.2D).

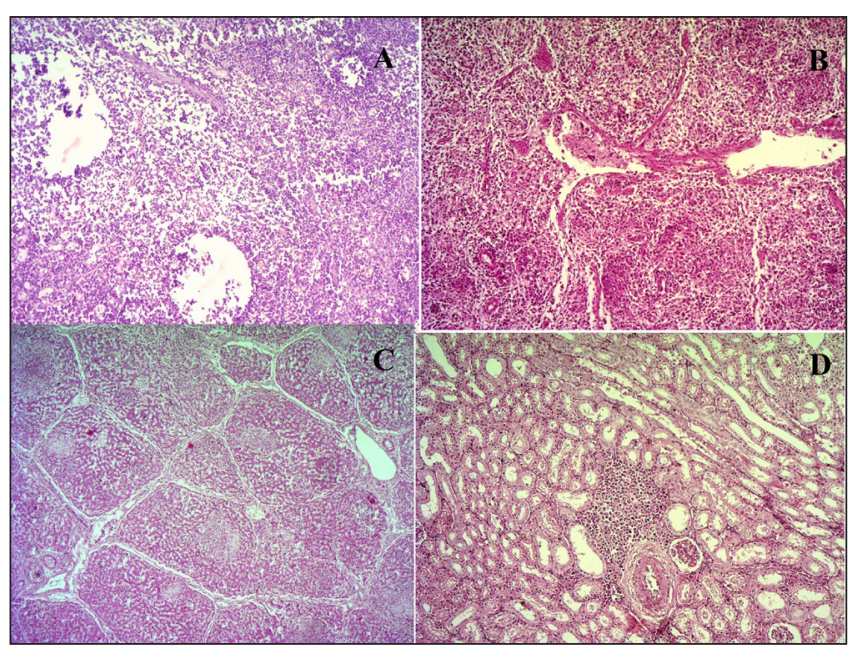

Fig. 1: Histopathological lesions in subclinical infection of PCV2 in piglets - (A) Piglet- Lymph node - Multifocal to diffuse, variable degree of lymphocyte depletion in the paracortical or follicular zones HE×100; (B) Piglet- Spleen- Diffuse moderate lymphoid depletion with reticulum cell hyperplasia - HE $\times$ 100; (C) Piglet- Liver- Multifocal coagulative necrosis with infiltration of lymphoplasmacytes - HE $\times 100$, (D) PigletKidney-Focal lymphoplasmacytic interstitial nephritis- HE $\times$ 100

Spleen showed distinct, multifocal, severe lymphoid depletion around the periarteriolar lymphoid sheath in white pulp (Fig. 2E), extensive coagulative necrosis of lymphoid cells in white pulp (Fig. 2F) with severe infiltration of numerous neutrophils and macrophages and hyperplasia of reticuloendothelial cells and vasculitis. Multifocal, severe follicular necrosis of lymphoid cells of Peyer's patches were characteristic.

Mild to severe lymphohistiocytic infiltration with sloughing of mucosal or glandular epithelial cells was observed in intestine. Severe diffuse subacute bronchointerstitial pneumonia (Fig. 2G) with numerous lymphocytes and macrophages, loss of bronchiolar epithelial cells and accumulation of lymphocytes in the lumen and presence of intracytoplasmic inclusions in the alveolar septa were the most usual lesion observed in lungs. Secondary bacterial infection led to the appearance of suppurative broncopneumonia in a few piglet tissues.

Hepatic lesions consisted of diffuse fatty changes or vacuolar degeneration of hepatocytes in the portal areas with progression to multifocal extensive coagulative necrotizing hepatitis with infiltration of lymphocytes and macrophages and multinucleated giant cells.

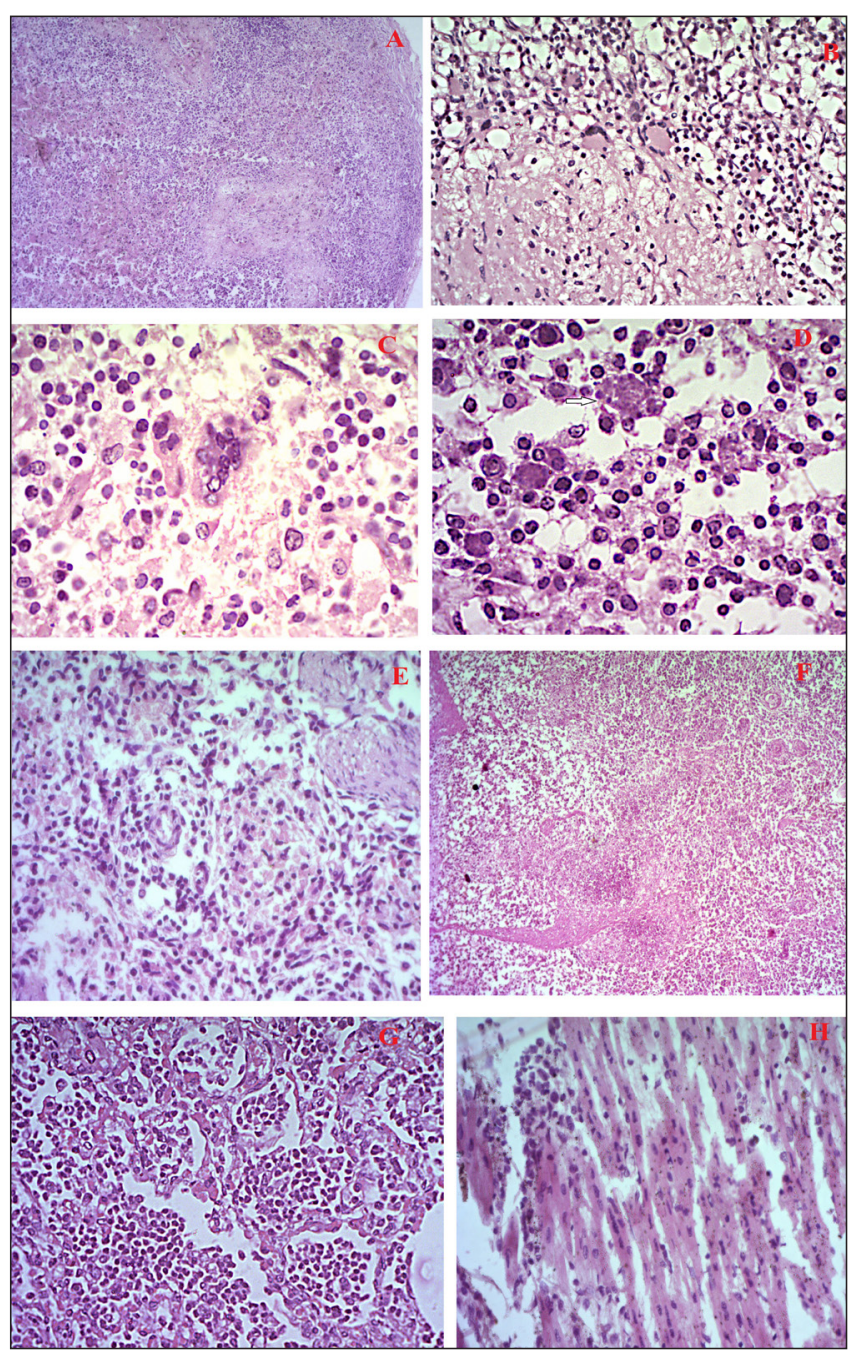

Fig. 2: Histopathological lesion in clinical infection of PCV2 in piglets - (A) Piglet- Lymph node - Severe lymphoid necrosis in follicles HE X100; (B) Piglet- Lymph node - Severe lymphoid necrosis in follicles bordered with macrophages and multinucleated giant cells HE X400; (C) Piglet- Lymph node - Syncytia formation- HEX 400; (D) Piglet- Lymph nodeSpherical bluish pink, sharply demarcated, variably sized botyroid inclusions in the cytoplasm of macrophages (arrow)HE $\times 1000$; (E) Piglet- Spleen- Distinct, multifocal, severe lymphoid depletion around the periarteriolar lymphoid sheath (arrow) in white pulp; (F) Piglet- Spleen- Extensive coagulative necrosis of white pulp- HE X100; (G) Piglet- Lung- Severe diffuse lymphohistiocytic interstitial pneumonia- HE X400; (H) Piglet- One week- Heart- Focal non suppurative myocarditis HE X400 
Moderatetoseveremultifocalextensivelymphoplasmacytic interstitial nephritis was a common finding with stray appearance of clusters of inclusions in tubular epithelial cells. Focally extensive non suppurative myocarditis with infiltration of lymphocytes and macrophages were observed in the heart tissues of one-week old piglets (Fig. $2 \mathrm{H})$.

Distribution and the severity of lesions in the parenchymatous tissues increased accompanied with the suppurative lesions of secondary bacterial infection in a few tissues compared to the subtle subclinical form of the disease. The lesions observed were in concurrence with the PCV2 associated systemic disease (Rosell et al., 1999; Segales et al., 2004; Segales, 2012) which was unnoticed because of the sporadic mortality pattern among piglets and inconsistent and non-specificity of the lesions in the organs. Though the histological lesions were typical of PCV2 infection in swine, the possibility of PCV2 infection was overlooked since there were no reports on the prevalence of PCV2 in southern India and also because the probable route of transmission of virus into the farm was untraceable, until the unprecedented occurrence of a full blown reproductive failure leading to abortions, still births and mummified fetuses in primiparous gilts which was reported earlier Karuppannan et al. (2014).

PCR amplification of DNA fragments from formalin fixed tissues is a simple and sensitive method and allows the reliable detection of PCV2 DNA (Kim and Chae, 2004). PCR assay performed with DNA extracted from the formalin fixed tissues showed specific amplification product of 620 base pairs confirming the presence of PCV2 ORF2 genome in the tissues (Fig. 3) was Realtime PCR run? if not, how can we comment on 'load' of viru?. Samples from myocardium, liver and spleen were found to be most suited for routine PCV2 testing by PCR (Mikami et al., 2005; Brunberg, et al., 2007). Sanchez et al. (2001) reported that PCV2 target cell changes from cardiomyocytes, hepatocytes and macrophages during fetal life to only macrophages postnatally.

Histopathological lesions are an important criterion for diagnosis of PCV2 infection in piglets and the microscopic lesions in lymphoid tissues were unique to PCV2. However, the involvement of the parenchymatous organs has to be differentially diagnosed from other porcine disease in piglets. The variation in the organ involvement makes it imperative that a wide range of lymphoid and parenchymatous tissues is to be collected at necropsy from piglets without overt clinical signs and also from piglets with unthriftiness and poor weight gain since the PCV2 associated systemic lesions may involve one organ system and no lesion in other organs. Detection of PCV2 nucleic acid when interpreted with characteristic histopathological changes in tissues provided a confirmatory diagnosis.

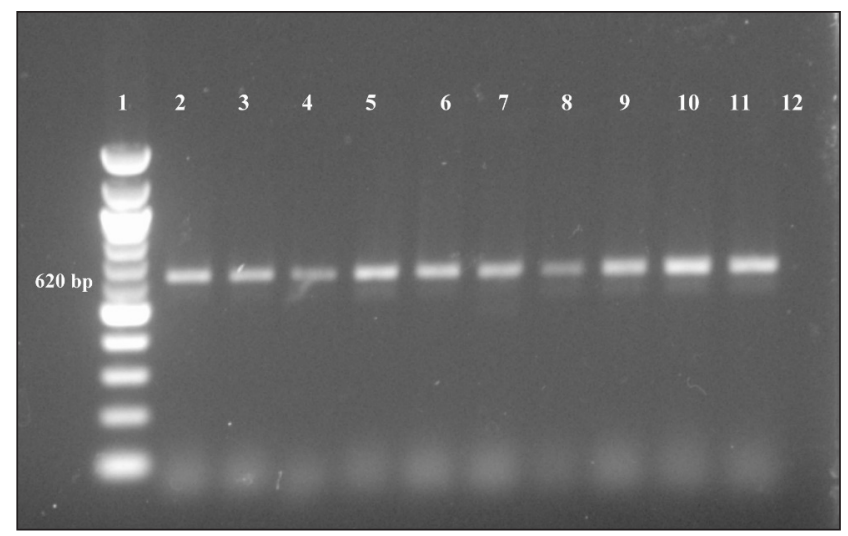

Fig. 3: PCR assay performed with DNA extracted from the formalin fixed tissues showed specific amplification product of 620 base pairs confirming the presence of PCV2 ORF2 genome in the tissues

Lane 1 - 100 bp ladder; Lane 2 - positive control; Lane 3 to 11 DNA from formalin fixed tissues; Lane 12 - negative control

\section{REFERENCES}

Allan, G.M. and Ellis, J.A. 2000. Porcine circoviruses: A review. J. Vet. Diagn. Invest., 12(1): 3-14.

Brunberg, I.M., Jonassen, C.M., Moldal, T., Bratberg,B., Koenen, L.F. and Schonheit, J. 2007. Association of myocarditis and high viral load of PCV2 in several tissues in cases of fetal death and high mortality in piglets. A case study. J. Vet. Diagn. Invest., 19(4): 368 -375.

Karuppannan, A.K., Ramesh, A., Reddy, Y.K., Ramesh, S., Mahaprabhu, R., Jaisree, S., Roy, P., Sridhar, R., Pazhanivel, N., Sakthivelan, S.M., Sreekumar, C., Murugan, M., Jaishankar, S., Gopi, H., Purushothaman, V., Kumanan, K. and Babu, M. 2016. Emergence of Porcine circovirus 2 associated reproductive failure in southern India. Transboud. Emerg. Dis., 63(3): 314-20.

Chae, C. 2004. Postweaning multisystemic wasting syndrome: a review of aetiology, diagnosis and pathology. Vet. J., 168(1): 41-49. 
Kim,J. and Chae, C. 2001. Differentiation of PCV1 and 2 in formalin fixed paraffin wax embedded tissues from pigs with postweaning multisystemic wasting syndrome by insituhybridisation. Res. Vet. Sci., 70: 265-269.

Kim, J. and Chae, C. 2003. Multiplex nested PCR compared with insitu-hybridisation for the differentiation of porcine circoviruses and porcine parvoviruses from pigs with postweaning multisystemic wasting syndrome. Canadian $J$. Vet. Res., 67(2): 133-137.

Krakowka, S., Ellis, J., McNeilly, F., Waldner, C. and Allan, G. (2005). Features of Porcine circovirus -2 disease: correlation between lesions, amount and distribution of virus and clinical outcome. J. Vet. Diagn. Invest., 17: 213-222.

Mikami, O., Nakajima, H., Kawashia, K., Yoshi, M. and Nakajima. Y. 2005. Nonsuppurative myocarditis caused by porcine circovirus type 2 in a weak born piglet. J. Vet. Med. Sci., 67(7): 35-38.

Opriessnig, T., Meng, X.J. and Halbur, P.G. 2007. Porcine circovirus type- 2 associated disease: Update on current terminology, clinical manifestations, pathogenesis, diagnosis and intervention strategies. J. Vet. Diagn. Invest., 19(6): 591615.

Rosell, C., Segales, J., Plana-Duran, J., Balasch, M., RodriguzAriraja., G.M., Kennedy, S., Allan, G., McNeilly, F., Latimer, K.S. and Domingo, M. 1999. Pathological, immunohistochemical and insitu-hybridisation studies in natural cases of postweaning multisystemic wasting syndrome in pigs. J. Comp. Pathol., 120: 59-78.
Sanchez Jr. R.E., Nauwyncka, H.J., McNeill, F., Allan, G.M., Pensaerta, M.B. 2001. Porcine circovirus 2 infection in swine foetuses inoculated at different stages of gestation. Vet. Microbiol., 83: 169-176.

Sarli, G., Mandriole, S., Panarere, B., Brunetti, J., Segales, J., Dominguez. J. and Marcato, P.S. 2008. Characterisation of interstitial nephritis in pigs with naturally occurring postweaning multisystemic wasting syndrome. Vet. Pathol., 45(1): $12-8$.

Segales, J., Rosell, C. and Domingo, M. 2004. Pathological findings associated with naturally acquired porcine circovirus type 2 associated disease. Vet. Microbiol., 98: 137-149.

Segalés, J. 2012. Porcine circovirus type 2 (PCV2) infections: clinical signs, pathology and laboratory diagnosis. Virus Res., 164(1-2): 10-19.

Zhai, S.L., Lu, S.S., Wei, W.K., Lv, D.H., Wen, X.H., Zhai, Q., Chen, Q.L., Sun, Y.W. and Xi, Y. 2019. Reservoirs of Porcine Circoviruses: A Mini Review. Front. Vet. Sci., 6: 319. 
